\title{
PERMANÊNCIA NA UNIVERSIDADE E A POLÍTICA DE ASSISTÊNCIA ESTUDANTIL NA UFPA: PROGRAMAS DE ASSISTENCIA ESTUDANTIL
}

\author{
Ellana Barros Pinheiro ${ }^{1}$
}

Resumo: A Universidade Federal do Pará (UFPA) conquista cada dia mais um espaço de destaque na produção e socialização do conhecimento científico, sua atuação possibilita uma maior aproximação entre universidade e população, de forma a garantir a articulação política de suas ações com excelência e legitimidade social. Com base no Programa Nacional de Assistência Estudantil (PNAES), a UFPA apresenta uma rede de apoio em conformidade com as prioridades da assistência estudantil em busca da efetividade institucional, com isso, a Diretoria de Assistência e Integração Estudantil da Pró-Reitoria de Extensão (DAIE) foi criada em 2007 com o objetivo de atender os diversos aspectos relativos à política de assistência aos estudantes da UFPA, e vem atuando no desenvolvimento de programas que visam garantir a permanência, o bem-estar, a melhoria do desempenho acadêmico e o êxito na conclusão da graduação. Portanto, este trabalho tem o propósito de apresentar as diversas atividades relativas que buscam proporcionar a permanência do discente na universidade, materializadas pela política, pelos programas e projetos que se desenvolvem desde 2009, por meio de pesquisa bibliográfica e documental através de estudos de relatórios institucionais e técnicos, documentos, editais, relatos, instruções normativas, entre outros, assim como por intermédio de estudo do Sistema Gerencial de Assistência Estudantil-Sigaest, no qual gerencia todos os auxílios assistenciais da universidade.

Palavras-chave: Permanência, UFPA, Assistência Estudantil.

Abstract: The Federal University of Pará (UFPA) wins every day more a prominent space in the production and socialization of scientific knowledge, his performance enables a closer relationship between the university and the population in order to ensure the political articulation of their actions with excellence and social legitimacy. Based on the Programa Nacional de Assistência Estudantil (PNAES), UFPA has a support network in accordance with the priorities of student assistance in pursuit of institutional effectiveness, therefore, the Diretoria de Assistência e Integração Estudantil da Pró-Reitoria de Extensão (DAIE) was

\footnotetext{
${ }^{1}$ UFPA; Especialista em Políticas Públicas e Serviço Social; Assistente Social da Diretoria de Assistência e Integração Estudantil (DAIE/PROEX/UFPA); Discente do curso de Mestrado em Serviço Social do Programa de Pós-Graduação de Serviço Social-UFPA, ellana@ufpa.br.
} 
established in 2007 in order to meet the various aspects of welfare policy to students of UFPA, and has been active in the development of programs to ensure the permanence, welfare, improved academic performance and success at the conclusion of graduation. Therefore, this paper aims to present the various activities related to seek to provide the permanence of students at the university, embodied by the policy, the programs and projects that develop since 2009, through bibliographical and documentary research through institutional study reports and technical documents, notices, reports, regulatory instructions, among others, as well as through study Sistema Gerencial de Assistência Estudantil-Sigaest, which manages all the assistance of university aid.

Keywords: Programa Permanência, UFPA, Student Assistance.

\section{Introdução}

Segundo o Plano de Desenvolvimento Institucional, a UFPA com base no PNAES, apresenta uma rede de apoio em conformidade com as prioridades da assistência estudantil "como direito e espaço prático de cidadania e de dignidade humana, em busca da efetividade institucional, uma vez que muitos jovens chegam à universidade sem condições mínimas de cultura, de lazer e, principalmente, de permanência em sua graduação” (PDI, 2015).

A Diretoria de Assistência e Integração Estudantil pertencente à Pró-Reitoria de Extensão (DAIE) da Universidade Federal do Pará foi criada em 2007 com o objetivo de atender os diversos aspectos relativos à política de assistência aos estudantes da UFPA. Em busca desse objetivo, a DAIE sob o mandato de Ney Cristina Monteiro de Oliveira como diretora, utilizou o Questionário Socioeconômico e Cultural (QSEC) realizado em 2008, para levantar as características socioeconômicas dos discentes de graduação, com a finalidade de reunir todas as informações sobre o corpo discente da universidade para auxiliar a concepção, o planejamento e a execução de políticas afirmativas e programas institucionais, além de proporcionar socialização e debate dos estudos feitos e a possibilidade de atendimento efetivo dos estudantes.

A partir do QSEC, houve a elaboração do projeto identificado como Programa Bolsa Permanência, com previsão para vigorar em 2009, objetivando a princípio “diminuir a retenção e o êxodo dos estudantes, através de auxilio alimentação, transporte, moradia e apoio pedagógico para estudantes em que for evidenciada, a partir do QSEC, a carência de recursos" (OLIVEIRA et al, 2008, p.9). A metodologia para a "concessão" do programa Bolsa Permanência foi prevista para se realizar com visitas domiciliares e entrevistas. 
Portanto, em 2009, como previsto, foi lançado o primeiro edital correspondente às ações da política de assistência estudantil na universidade, com a portaria $\mathrm{N}^{\mathrm{o}} 1409$ de 2009 , destinando-se a identificar e selecionar alunos de graduação em situação de vulnerabilidade socioeconômica, visando a oferta de apoio para alimentação, transporte, moradia, atividades didático-pedagógicas e atividades acadêmicas, além do acesso ao atendimento psicossocial, promovendo a permanência do estudante durante o tempo regular do seu curso.

\section{Objetivos/ Metodologia}

Este trabalho tem o propósito de apresentar as diversas atividades relativas que buscam proporcionar a permanência do discente na universidade, materializada pela política, pelos programas e projetos que se desenvolvem desde 2009, primeiro edital do "Bolsa Permanência" por meio de pesquisa bibliográfica e documental através de estudos de relatórios institucionais e técnicos, documentos, editais, relatos, instruções normativas, entre outros.

\section{Resultados}

Os Programas de Assistência Estudantil desenvolvidos pela DAIE/PROEX, atualmente, apresentam atividades e objetivos que são regidos pelos princípios gerais do Programa Nacional de Assistência Estudantil do Ministério da Educação. São eles: O Programa Alimentação Estudantil, almejando contribuir para a permanência do estudante na universidade e a sua formação integral, proporcionando alimentação de qualidade, balanceada e variada, para isso, o programa conta com os restaurantes universitários. $\mathrm{O}$ Restaurante Universitário da UFPA, unidade da Pró-Reitoria de Administração da UFPA, foi inaugurado em 01 de outubro de 1993, e iniciou suas atividades em 13 de outubro do mesmo ano, com sua estrutura física projetada para o atendimento de até 1.200 refeições. Hoje a UFPA, apresenta dois restaurantes: localizam-se no Campus Profissional e Básico em Belém, dispõe da oferta de em média 2600 refeições no almoço e 800 no jantar, no qual o estudante a obtém no valor de $\mathrm{R} \$ 1,00$. O custo global de cada refeição, para a Universidade, varia em torno de 5 a 6 reais. Subsidiada, em grande parte, com recursos da Assistência Estudantil (UFPA, 2015).

Dentro da perspectiva de alimentação e assistência estudantil, em 2010, foi criado oficialmente o Programa de assistência estudantil Taxa Zero, auxílio destinado aos estudantes 
de baixa renda identificados em situação de vulnerabilidade socioeconômica à isenção do pagamento da taxa para alimentação na universidade, tanto no almoço quanto no jantar.

Atualmente, o programa taxa zero dispõe de 200 vagas para estudantes do campus Belém e o perfil do estudante destinado ao programa é identificado através da seleção do Programa Permanência, ou seja, não há inscrição por demanda espontânea nem edital referente a este auxilio. O "taxa zero" é destinado somente aos alunos do município de Belém, porque é o único campus que dispõe de restaurantes universitários. Outro programa de assistência estudantil desenvolvido na UFPA é o Programa Estudante Saudável, seu objetivo é promover ações de saúde no âmbito individual e coletivo, que abranjam assistência e atendimento à saúde, a prevenção de agravos, o diagnóstico e o tratamento de baixa complexidade, visando o bem-estar e a qualidade de vida do discente de graduação da UFPA, contribuindo assim, para sua permanência e conclusão de seu curso por meio das ações e serviços de:

- Assistência odontológica e preventiva, oferecendo serviço de assistência à saúde bucal aos estudantes, como cuidados de urgência e emergência e várias especialidades, disponibilizado pelas Clínicas da Faculdade de Odontologia;

- Clínica de Psicologia, oferecendo serviços voltados à prevenção, manutenção e recuperação da saúde psicológica, o atendimento é disponibilizado na Clínica de Psicologia da UFPA;

- Ações voltadas para prevenção de câncer em estudantes universitárias, desenvolvendo ações visando à prevenção de doenças infecciosas e do câncer de colo do útero, de mama e do aparelho respiratório, sendo as discentes atendidas em laboratórios específicos no prédio do Instituto de Ciências Biológicas;

- Serviço de Assistência Psicossocial aos Discentes (SAPS), que oferece ações de atendimento médico, psicológico, social, familiar e pedagógico aos discentes e membros de $1^{\circ}$ grau de sua família, sendo atendidos no Instituto de Ciências da Saúde da UFPA;

- Consultas pré-agendadas no Hospital Universitário Bettina Ferro de Souza (HUBFS) e Hospital Universitário João de Barros Barreto (HUJBB), unidade de saúde, médico, ambulatorial e hospitalar. Esta ação dos hospitais universitários apresenta a proposta de parceria com a assistência estudantil, visando o 
atendimento de alunos que necessitem de atendimentos médico, exames complementares e cirurgias ambulatoriais no período de permanência universitária.

Os atendimentos do Programa Estudante Saudável são destinados aos alunos de graduação da UFPA de baixa renda, preferencialmente. Para acessar a esses serviços, o estudante é encaminhado pela DAIE/PROEX mediante autorização e consulta prévia com um médico clínico geral da Equipe multiprofissional da diretoria.

O Programa Moradia Estudantil também está em acordo com Programa Nacional de Assistência Estudantil (PNAES), instituído pelo Decreto 7.234/2010 e complementado pelo Decreto 7.416/2010, mas também pela Resolução/CONSUN/UFPA No 704, de 26 de janeiro de 2012, que instituiu o Regulamento da Casa de Estudantes Universitários da UFPA, em consonância com a Resolução N 657 de 23 de dezembro de 2008 que regulamenta o Código de Posturas dos estudantes contemplados.

O programa é destinado a selecionar estudantes dos cursos de graduação da UFPA, em situação de vulnerabilidade socioeconômica e que se encontrem sem condições de arcar com o custo de moradia fora de seu local de origem, ou seja, visa proporcionar aos discentes, acolhimento e condições habitacionais adequadas à sua permanência e desenvolvimento acadêmico, impulsionando a inserção social ao pleno exercício de sua cidadania, durante o tempo regular do curso de graduação até a diplomação.

As vagas da Casa de Estudantes Universitários da Universidade Federal do Pará (CEUS-UFPA) destinada a oferecer moradia temporária gratuita a alunos regularmente matriculados de reconhecida carência de recursos financeiros, são preenchidas, preferencialmente, por alunos de Graduação e, ocorrendo vagas, em até $10 \%$ de PósGraduação que não tenham vínculo empregatício.

A casa é coordenada administrativa e financeiramente pela DAIE, na forma de uma Equipe Multidisciplinar, sendo constituída, no mínimo, por um assistente social, um pedagogo e um psicólogo. Esta equipe apresenta como competências: coordenar e supervisionar o processo de triagem e seleção dos candidatos à moradia, promover entrevista individual com os candidatos e, quando necessário, realizar visita domiciliar; Informar e orientar os novos residentes sobre as normas e funcionamento da casa, orientar e encaminhar os residentes aos serviços oferecidos pela UFPA nas áreas médica, odontológica e psicossocial e manter com os residentes das casas atividades culturais e de integração (com as comunidades interna e externa da Instituição). 
Internamente, é administrada por no mínimo três representantes discentes e no máximo cinco, indicados e escolhidos em assembleia entre seus residentes, havendo para cada CEUS uma coordenação de discentes residentes.

Atualmente a DAIE/PROEX mantêm casas para estudantes nos municípios de Belém (exclusivo para mulheres), Altamira, Breves, Castanhal e Tucuruí. O processo de seleção de estudantes para ocupação das vagas nas residências é feito de acordo com o surgimento de vagas. A assistência estudantil também e responsável pela mobília e manutenção das casas.

E finalmente o grande Programa Permanência, programa de assistência estudantil de maior porte na UFPA, que apresenta o objetivo de atender e selecionar estudantes de cursos de graduação em situação de vulnerabilidade socioeconômica, cursando a primeira graduação e que não possuem condições de arcar com custeio total ou parcial com alimentação, moradia, material didático-pedagógico e transporte até a universidade, promovendo o apoio à permanência deste estudante na universidade, assim como garantir a igualdade de oportunidades aos estudantes na perspectiva do direito social, proporcionando condições básicas e assegurando aos estudantes os meios necessários ao pleno desempenho acadêmico. Este olhar de atenção aos estudantes, em tese, contribui para melhoria do sistema universitário, haja vista que prevenindo e erradicando a retenção e a evasão acadêmica, quando decorrentes de dificuldades socioeconômicas e emocionais.

O Programa Permanência desenvolvido na DAIE/PROEX apresenta 12 modalidades de auxílios: Auxílio Permanência e Moradia; Auxílio Permanência e Moradia Intervalar; Auxílio Permanência Especial (PcD); Auxílio Creche; Auxílio Estudante Estrangeiro; Auxílio Emergencial; Auxílio Kit Acadêmico; Auxílio Kit Acadêmico Especial ( $\mathrm{PcD}$ ); Auxílio Instruir; Auxílio Casa do Estudante; PROLÍNGUAS ou Auxílio Acesso às Línguas Estrangeiras, Bolsa de Apoio à Atividade Acadêmica (I e II).

\section{Conclusões}

Essas modalidades de auxílios com base em critérios socioeconômicos apoiam os estudantes com o recebimento de benefício financeiro, oportunizando a permanência do estudante durante o tempo regular do seu curso até sua diplomação. Os números de auxílios disponíveis são previstos de acordo com os recursos disponíveis de assistência estudantil a cada ano, podendo ser ampliados ou retraídos. Contudo, os estudantes selecionados comprometem-se a cumprir com as atividades acadêmicas das disciplinas ao longo de seu curso de graduação, visando a sua diplomação dentro do prazo previsto para a sua 
integralização curricular, assim como manter-se matriculado durante todo o período de gozo do auxílio.

Os discentes contemplados com os auxílios terão seus desempenhos acadêmicos avaliado em todas as etapas de vigência do auxílio, e deverão obter um bom Coeficiente de Rendimento (CR) para continuar recebendo o auxílio, sendo a avaliação do desempenho acadêmico realizada semestral e anualmente.

\section{Referências}

PLANO DE DESENVOLVIMENTO INSTITUCIONAL. PDI/UFPA 2011-2015 Disponível em: < http://www.proplan.ufpa.br/doc/pdi/PDI_2011-2015.pdf >. Acessado em: 28 novembro de 2015.

UNIVERSIDADE FEDERAL DO PARÁ. Pró-Reitoria de Extensão. Programas de Assistência Estudantil. Belém. PROEX/DAIE, 2015. Disponível em: <http://proex.ufpa.br/PRINCIPAL/index.php/politicadeassistencia >. Acessado em: 01 de março de 2015.

OLIVEIRA, Ney Cristina Monteiro de. BARBOSA, Leonardo Patrício Ferreira. SILVA, Sâmia Mota da. FIGUEIREDO, Ricardo Coutinho. ROCHA, Ana Carolina de Araújo. QSEC (Questionário Socioeconômico e Cultural) Inclusão e diversidade: a experiência da UFPA, 2008. Disponível em:<

http://www.geedh.ufpa.br/sites/default/files/1._qsec_inclusao_e_diversidade_a_experiencia_ da_ufpa.pdf $>$. Acesso em 17 de fevereiro de 2015. 